\title{
Perineal metastatic Crohn's disease: a case report and review of the literature
}

\author{
LH MOYES, P GLEN, IR PICKFORD \\ Department of Surgery, Victoria Infirmary, Glasgow, UK
}

\begin{abstract}
Metastatic Crohn's disease is an uncommon complication of Crohn's disease defined as granulomatous inflammation not contiguous with inflammatory disease in bowel. We report on the presentation and management of a 36-year-old man, who had undergone panproctocolectomy II years ago, with complex fistulous disease in his perineum, which demonstrated granulomas histologically after resection. We review six similar case reports. Optimal treatment would appear to be by surgical debridement.
\end{abstract}

Keywords: Perineal sepsis - Crohn's disease - Surgical management

Patients with Crohn's disease may exhibit a variety of cutaneous disorders such as pyoderma gangareneosum, erythaema multiformae, aphthous ulcers, erythema nodosum and necrotising vasculitis. ${ }^{1}$ While these skin pathologies can be found in diseases other than Crohn's disease, skin lesions demonstrating characteristic granulomas of Crohn's histologically, are specific to Crohn's disease and are termed metastatic Crohn's disease if not contiguous with bowel inflammatory change. This was first described in $1976 .^{2}$

Metastatic Crohn's disease of the perineum is uncommon and can manifest several years after an apparently successful proctectomy. Medical treatment of this condition appears to have a poorer outcome than surgical debridement. We report on a case that was treated by aggressive surgical debridement and intensive specialist nurse input.

\section{Case report}

A 39-year-old male presented as an out-patient in July 2005 with a 12-month history of pain and discharge from the perineum. He had been diagnosed with Crohn's disease 24 years previously. This had initially been managed with medical therapy but his symptoms progressed and, in 1986,

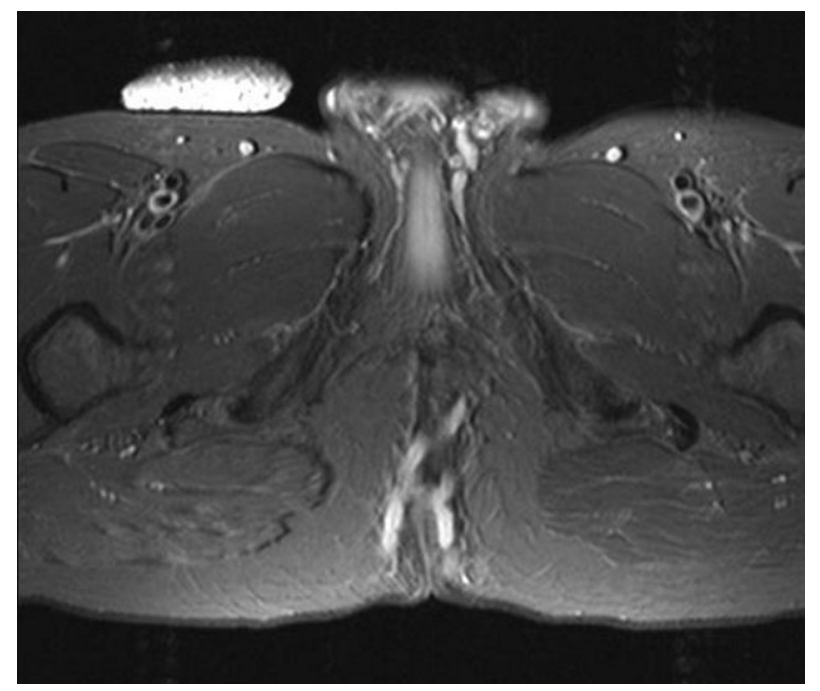

Figure I MRI scan of perineal fistula track.

Correspondence to: Paul Glen, Department of Surgery, Victoria Infirmary, Langside Road, Glasgow G42 9TY, UK T: +44 (0) I4I 20 I 5।72; F: +44 (0) I4I 20| 5452; E: paul.glen@ntlworld.com 
Table I Review of case reports in literature

\begin{tabular}{|c|c|}
\hline Reference & Williams et al. $(1993)^{3}$ \\
\hline Age (years) & 25 \\
\hline Sex & $\mathrm{M}$ \\
\hline Presentation & Perineal discharge and sinuses. Previous panproctocolectomy 5 years before \\
\hline Symptom duration (years) & 5 \\
\hline Initial management & Prednisolone, azathioprine, dapsone, antibiotics, hyperbaric oxygen failed \\
\hline Treatment & Extensive surgical debridement \\
\hline Outcome & At 1 year, few sinuses remain but healed well \\
\hline Reference & Williams et al. $(1993)^{3}$ \\
\hline Age (years) & 50 \\
\hline Sex & M \\
\hline Presentation & Chronic perineal discharge from sinuses \\
\hline Symptom duration (years) & $3-4$ \\
\hline Initial management & Proctectomy failed \\
\hline Treatment & Extensive debridement and split skin graft \\
\hline Outcome & Healed with no sepsis 16 months later \\
\hline Reference & Williams et al. $(1993)^{3}$ \\
\hline Age (years) & 54 \\
\hline Sex & M \\
\hline Presentation & Chronic perineal sinus \\
\hline Symptom duration (years) & 26 \\
\hline Initial management & Conservative debridement of sinuses but sepsis continued. Azathioprine/cyclosporin failed \\
\hline Treatment & Debridement and split skin graft 3 years post-presentation \\
\hline Outcome & Good - minimal discharge 10 months later \\
\hline Reference & Williams et al. $(1993)^{3}$ \\
\hline Age (years) & 48 \\
\hline Sex & $\mathrm{F}$ \\
\hline Presentation & Perineal discharge. Panproctocolectomy and ileostomy for Crohn's disease 13 years before \\
\hline Symptom duration (years) & 5 \\
\hline Initial management & Cyclosporin/metronidazole initial improvement then failed \\
\hline Treatment & Extensive debridement down to deep fascia. Closure - secondary intention \\
\hline Outcome & Complete healing 1 year later \\
\hline Reference & Williams et al. $(1993)^{3}$ \\
\hline Age (years) & 23 \\
\hline Sex & $\mathrm{F}$ \\
\hline Presentation & Peri-anal Crohn's disease - subtotal colectomy and ileostomy. Developed peri-anal discharge \\
\hline Symptom duration (years) & 7 \\
\hline Initial management & Steroids, azathioprine, metronidazole and mercaptopurine \\
\hline Treatment & Extensive perineal and vaginal excision with reconstruction flap \\
\hline Outcome & Good results at 6 months \\
\hline Reference & Sangueza and Davis $(1997)^{4}$ \\
\hline Age (years) & 24 \\
\hline Sex & $\mathrm{N}$ \\
\hline Presentation & Perineal ulceration. Past history of perirectal abscess (4 years previously) \\
\hline Symptom duration (years) & 1 \\
\hline Initial management & Prednisolone \\
\hline Treatment & Prednisolone - no surgical management needed \\
\hline Outcome & Good \\
\hline Reference & This case \\
\hline Age (years) & 36 \\
\hline Sex & M \\
\hline Presentation & Perineal sepsis. Previous panproctocolectomy 18 years ago \\
\hline Symptom duration (years) & 1 \\
\hline \multicolumn{2}{|l|}{ Initial management } \\
\hline Treatment & Extensive surgical debridement \\
\hline Outcome & Good \\
\hline
\end{tabular}

he underwent a subtotal colectomy with an ileorectal anastomosis. Postoperatively, he continued to have discharge from his perineum. A colonoscopy at that time showed a proctitis with an ulcerated lesion at his anastomosis. Medical therapy again was tried but failure of this led to a completion proctectomy the following year. 
Unfortunately, he was still troubled with occasional episodes of perineal discharge and was, therefore, maintained on oral steroids and salazopyrine. Five years later, he was relatively symptom-free and had discontinued all medications.

On presentation to out-patient clinic, he had multiple openings in his scrotum extending round to his perineum. His inflammatory markers were mildly elevated and MRI showed a complex H-shaped perineal fistula, giving rise to external openings in the perineum and up to the coccyx via a tract in the ischiorectal fossa. While awaiting an urgent review appointment, he required emergency deroofing of perineal sepsis. Despite this intervention, he was still troubled with perineal pain and discharge. A couple of weeks later, he underwent an examination under anaesthesia which largely confirmed the MRI findings (Fig. 1). Extensive debridement of the perineum was performed removing all affected tissue down to healthy tissue. Microbiological review of pus grew a group B streptococcus. Skin and granulation tissue was sent to pathology which demonstrated chronic inflammation with abscess formation along the sinus tracts with evidence of several non-caseating granulomas in keeping with Crohn's disease. The extensive wound was allowed to heal by secondary intention with expertise from a specialist tissue nurse. When he was reviewed 2 weeks later, there was significant improvement in his symptoms and the wound was healing well. To date, the wound has healed and he has required no further surgical input.

\section{Discussion}

The terms 'metastatic Crohn's disease', 'perineum' and review of relevant references yielded six case reports in adults. Our patient was included in the review. Details of all cases are displayed in Table 1 . The median age was 36 years and male:female ratio was 5:2. One patient presented with perineal ulceration responding to steroids. The remaining patients presented with perineal discharge and sinuses that did not respond to medical therapy and requiring surgical debridement, three with skin or flap graft. The outcome from surgery was good with no patient requiring further intervention.

\section{Conclusions}

Perineal sepsis containing granulomas characteristic of Crohn's disease can occur at a long interval following proctectomy. Medical therapy would only appear to be useful in very mild disease and treatment should be extensive surgical debridement with specialist nursing wound care. No cases have been published since Infliximab came into use and this may be of benefit, but the purpose of this report is to highlight the possibility of metastatic Crohn's disease and allow such patients to be considered for surgery rather than a lengthy period of medical therapy.

\section{References}

1. Burgdorf W. Cutaneous manifestations of Crohn's disease. J Am Acad Dermatol 1981; 5: 689-95.

2. McCallum DI, Gray WM. Metastatic Crohn's disease. Br J Dermatol 1976; 95: 551-4

3. Williams N, Scott NA, Watson JS, Irving MH. Surgical management of perineal and metastatic cutaneous Crohn's disease. Br J Surg 1993; 80: 1596-8.

4. Sangueza OP, Davis LS. Metastatic Crohn's disease. Southern Med J 1997; 90: 897-8. 